\title{
Outcome of Monteggia Fracture Dislocation in Children Treated With K Wires in Nepalgunj Medical College
}

\author{
Shrestha $\mathrm{S}^{1}$, Shrestha DK ${ }^{1}$
}

\begin{abstract}
Introduction: Monteggia fracture dislocations are rare injuries $(<5 \%)$ where missed treatment results into deformity and dysfunction of forearm and hand. For the better functional result early diagnosis, accurate reduction of radial head and rigid fixation of ulna and immobilization during post-operative period for ligamentous healing around radius is vital. So operative treatment has been the primary method of treatment to prevent deformity and disability in monteggia fracture dislocation. Aims: The aim of this study was to evaluate the time taken to unite fractures, complications encountered and assess the functional outcome on the basis of K-wire fixation in monteggia fracture dislocation in children. Methods: A cross-sectional observational study was conducted in Nepalgunj Medical College and Teaching Hospital, Kohalpur, Banke with monteggia fracture dislocation in children.Results: Thirty-two monteggia fracture dislocation in children between six to 14 years of age were treated with intramedullary K-wires after reduction of radial head. Seven cases had open reduction, and five needed trans-capitellar K-wire supplementation. Mean union time was $8.44 \pm 1.94$ weeks ranging from seven to 12 weeks. The functional outcome on the basis of Anderson's scoring system was excellent in $25(78.1 \%)$, good in three and optimal in four cases. Conclusion: Monteggia fracture dislocation is better treated early and early mobilization of elbow joint is needed for better functional results.
\end{abstract}

Keywords: Monteggia fracture dislocation, Radial head reduction

\section{Authors:}

1. Dr. Sabin Shrestha

2. Dr. Dinesh Kumar Shrestha

${ }^{1}$ Department of Orthopedics, Nepalgunj Medical College and Teaching Hospital, Kohalpur, Banke

\section{Address for Correspondence:}

Dr. Sabin Shrestha

Department Of Orthopaedics

Nepalgunj Medical College and Teaching Hospital

Kohalpur, Banke

Email : shtdsabin@gmail.com

\section{INTRODUCTION}

The forearm allows pronation and supination of hands, so it has a vital role in day-to-day activities. Impairment of forearm resulting from fractures has both short-term and long-term disability due to improper treatment. The particular type of fracture of proximal third ulna associated with radial head dislocation was first described by Giovanni Battista Monteggia and eponymously used as monteggia fracture dislocation by Perrin. ${ }^{1,2}$

Bado described the classification system into four types on the basis of direction of dislocation of radial and used broadly to guide treatment of this fracture. ${ }^{3,4}$ Management of monteggia fracture basically depends upon the stability of reduced radial head, and if it goes undiagnosed for more than four weeks it is neglected monteggia fracture dislocation. ${ }^{5-8}$

$\begin{array}{ll}\begin{array}{l}\text { Type I } \\ \text { (60\% of the } \\ \text { cases) }\end{array} & \begin{array}{l}\text { Extension injury, fracture at upper third of ulna } \\ \text { with anterior angulation at fracture site and } \\ \text { associated anterior dislocation of radial head }\end{array} \\ \begin{array}{l}\text { Type II } \\ \text { (15\% of the } \\ \text { cases) }\end{array} & \begin{array}{l}\text { Flexion injury, fracture of ulnar diaphysis with } \\ \text { posterior angulation at fracture site and posterior } \\ \text { or postero-lateral dislocation of radial head. }\end{array} \\ \begin{array}{l}\text { Type III } \\ \text { (20\% of the } \\ \text { cases) }\end{array} & \begin{array}{l}\text { Fracture at ulnar metaphysis with lateral or antero- } \\ \text { lateral dislocation of the radial head. }\end{array} \\ \begin{array}{l}\text { Type IV } \\ \text { (5\% of the } \\ \text { cases) }\end{array} & \begin{array}{l}\text { Fracture at the proximal third of radius and ulna at } \\ \text { the same level with anterior dislocation of radial }\end{array} \\ \text { head. }\end{array}$

Table I: Classification of the monteggia fracture dislocation ${ }^{3}$

Monteggia fracture is better described in children, though it's not that common, less than five percent of all forearm fractures. ${ }^{9}$ In past results of treatment of monteggia fracture was not so good as the fracture is inherently unstable resulting into permanent disabilities. ${ }^{10,11}$ Low incidence, unstable nature, interesting nature of mechanism of injury and poor 
outcome motivated us to do this study. ${ }^{12,13}$ So the aim of the study was to evaluate the effectiveness of surgical treatment of monteggia fracture dislocation with internal fixation with $\mathrm{K}$-wires in children.

\section{METHODS}

This cross-sectional study was done in 32 children between 6 to 14 years of age who were admitted in Nepalgunj Medical College Teaching Hospital, Kohalpur Banke from October 2018 to December 2020 who had fracture of shaft of ulna associated with proximal radioulnar joint dislocation or subluxation. All the patients were treated with open or closed reduction of fracture with intramedullary K- wires.

Informed and written consent were taken from parents / guardians and those who met the inclusion criteria and those willing to take part in this study were included.

\section{Inclusion criteria:}

- $\quad$ Age between six to 14 .

- $\quad$ Fracture of proximal ulna associated with dislocation or subluxation of radial head.

- $\quad$ Associated fracture of radial head or neck.

- Open and/or closed fracture of ulna.

\section{Exclusion criteria}

- $\quad$ Age above 15 and below six.

- $\quad$ Those not willing to give consent for the study.

- Neglected monteggia fracture dislocation.

- $\quad$ Patients who are medically unfit.

- Pathological fractures.

\section{Surgical techniques}

Under general anesthesia or brachial block, forearm was positioned on the radiolucent table. Tourniquet was applied and aseptic technique was followed. Initially dislocated radial head was tried to reduce using traction along the forearm and counter traction along the arm followed by flexion of elbow to $110-130$ degrees. $^{9}$ Reduced radial head was identified by palpation of radial head just below the lateral condyle and confirmed by fluoroscopy. Arm and elbow were held at 90 degree by the assistant and one centimeter incision was made at the olecranon process of elbow and artery forceps was used to reach the bone to clear off the soft tissue and intervening muscles. Then bone awl was used to pierce the cortex of olecranon in the line of ulna and it was progressed to the medullary canal of ulna. It was confirmed under fluoroscopy in antero-posterior and lateral view. Various sizes two to $2.5 \mathrm{~mm} \mathrm{~K}$-wires tip were cut and it was inserted into medullary canal through the entry point with T-handle. Once $\mathrm{K}$-wire reached the fracture site, ulna was aligned with traction over forearm and counter traction at elbow and K-wire was passed through fracture to the distal part of ulna and was confirmed with fluoroscopy. In case of fractures those which did not get reduced, it was opened over the fracture site along the longitudinal axis of ulna incising skin, subcutaneous tissue and fascia. The interval was developed between flexor carpi ulnaris and extensor carpi ulnaris. Enough periosteum was stripped away from each fracture site using periosteum elevator. Fracture hematoma was cleared and curetted. Accurate anatomical reduction was performed and K-wire was passed to the distal end of ulna till the distal physis of the ulna and it was confirmed with fluoroscopy. The incision was closed in layers and once again the radial head reduction was checked to prevent redislocation. If it was dislocated, it was reduced and supplemented with trans-capitellar $\mathrm{K}$ - wire into the radius in flexed position of elbow at 100 to 110 degree. Once secured fixation was achieved, sterile dressing was done and above elbow posterior plaster of Paris slab in supination, was applied in 100 to 110 degree of flexion at elbow after removing tourniquet. ${ }^{14}$ Post-operative X-ray was done on the first post-operative day.

Those who underwent open reduction and K-wire fixation iv antibiotics were continued for 3 to 5 days and changed into oral. Alternate dressing was done and stitches were removed on $14^{\text {th }}$ day. They were followed on first week, third week and every month till the removal of implant. Check Xray was taken on every follow up and assessed the radiological union. Above elbow slab was removed on the third week and arm sling was applied to maintain elbow flexion to $110^{\circ}$ to $120^{\circ}$. Intermittent range of motion was advised. At final follow up, functional outcome was accessed on the basis of Anderson's scoring system.

\section{Statistical analysis:}

SPSS version 25 was used to perform statistical analysis and $p$ value $<0.05$ was considered statistically significant. Chi square test was used to analyze functional outcome. Mean and standard deviation were calculated for all measured and calculated values.

\section{RESULTS}

Thirty-two patients were included in the study with the mean age of $7.84 \pm 1.32$ years ranging from six to 14 years with male predominance of $19(59.37 \%)$ cases as shown in table II. Male to female ratio was 1.5:1. Majority of cases resulted from fall, accounting to $29(90.63 \%)$ cases and three $(9.37 \%)$ had road traffic accidents. Twenty four cases had fracture on right side and eight cases had fracture on left side. 


\begin{tabular}{c|ccc}
$\begin{array}{c}\text { Age in } \\
\text { years }\end{array}$ & Female & Mex & Total \\
$6-10$ & 11 & 17 & 28 \\
$10-14$ & 2 & 2 & 4 \\
\hline Total & 13 & 19 & 32 \\
\hline
\end{tabular}

Table II: Age and sex distribution of cases

In the present study 27 cases had type I fracture, three type III and two type IV and none of type II fractures. Three cases were open fractures which were type I. It took approximately $22.75 \pm 4.6$ minutes to do the procedure ranging from 20 to 45 minutes. All the procedures were done on regular basis as early as possible, the range of operation days from the occurrence of incident to the operation was two to 5 days mean being $3.25 \pm 0.24$ days. In all cases radial head was reduced first and was confirmed with the radiograph. Twenty-five cases had closed reduction and seven cases need open reduction of ulna fracture and fixed with intramedullary K-wires as shown in table III.

\begin{tabular}{|c|cccc|}
\hline & & \multicolumn{3}{c}{ Type of reduction } \\
\hline $\begin{array}{c}\text { Types of } \\
\text { flosed }\end{array}$ & Open & Total \\
\hline $\begin{array}{c}\text { fractures on the } \\
\text { basis of Bado's } \\
\text { classification }\end{array}$ & Type III & 21 & 6 & $\begin{array}{c}27 \\
(84.4 \%)\end{array}$ \\
& Type IV & 2 & 1 & $\begin{array}{c}3 \\
(9.4 \%)\end{array}$ \\
& Total & $\mathbf{2 5}$ & $\mathbf{7}$ & $\begin{array}{c}2 \\
(\mathbf{6 . 1 3} \%)\end{array}$ \\
\hline & & $\mathbf{( 2 1 . 8 7 \% )}$ & $\mathbf{3 2}$ \\
$\mathbf{( 1 0 0 \% )}$
\end{tabular}

Table III: Distribution of types of fracture with the reduction method used

Five cases needed fixation of radius, through trans-capitellar $\mathrm{K}$-wire as they were unstable on fluoroscopy after fixation of ulna. Among five cases two were type I and one was type III and two were type IV. In three open fractures, first debridement was done and then ante grade intramedullary K-wires were done. Intraoperative procedures were uneventful. IV antibiotic cefuroxime was given in all cases for 3 days then it was changed to oral for 7 days more in closed fracture while in three open fractures it was given for five days and oral antibiotics was continued for 7 days more.

Twenty-three cases had above elbow slab for three weeks and seven cases with open reduction had slab for 4 weeks and two cases had it for five weeks.

\begin{tabular}{|lcc|}
\hline & \multicolumn{1}{c}{ Mean } & Range \\
\hline Evidence of callus & $3.31 \pm 0.52$ weeks & $3-5$ weeks \\
\hline Union & $8.44 \pm 1.94$ weeks & 7-12 weeks \\
\hline
\end{tabular}

Table IV: Duration showing evidence of callus and union
Trans capitellar pins were removed on third weeks in all five cases. In all cases range of motion was advised after removal of slab.

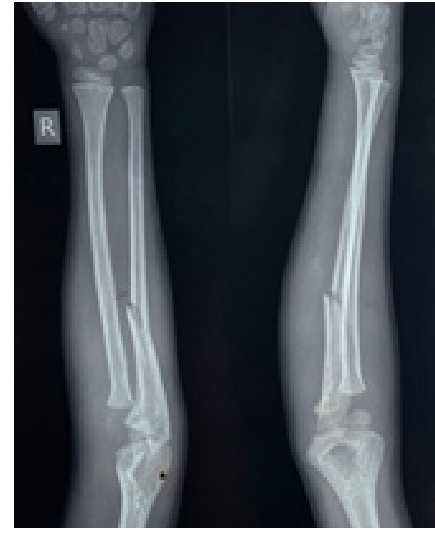

Figure 1: Bado's type I Monteggia fracture dislocation.

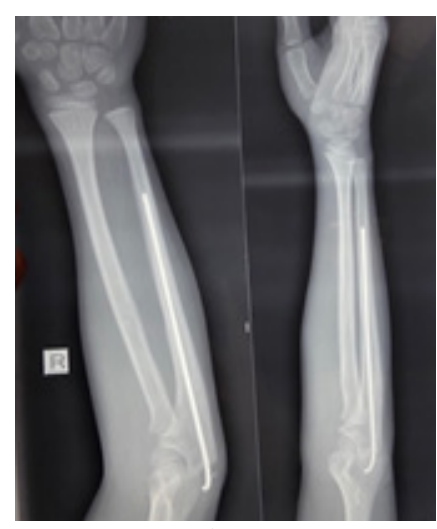

Figure 3: Eight weeks follow up case and X-ray before removal of implant.

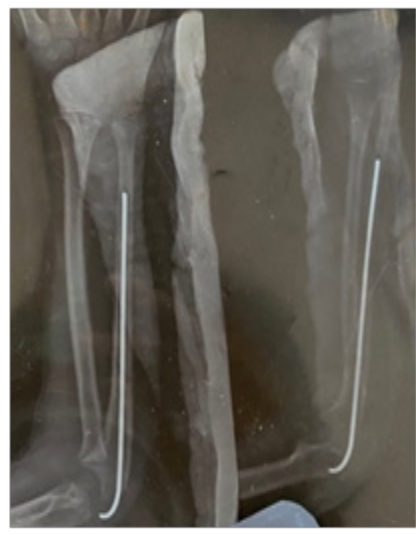

Figure 2: Immediate post-operative X-ray with intramedullary K-wire fixation of ulna

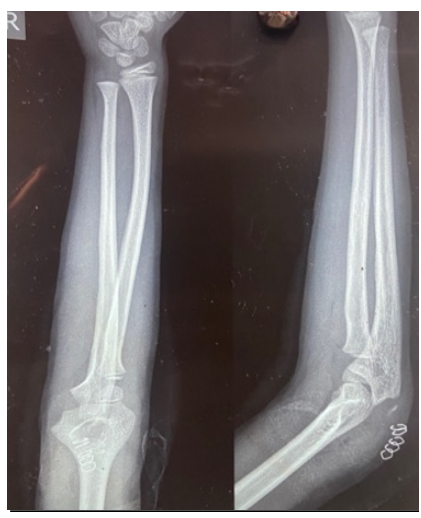

Figure 4: X-ray after removal of implant
Figure 1: Series of pictures showing monteggia fracture

Implants were removed on regular basis after at least three cortical union was seen, it was removed from 12 weeks to 18 weeks with mean duration of $12.81 \pm 1.94$ weeks. At final follow up, range of motion was accessed and loss of range of motion (flexion, extension, supination and pronation) were accessed as shown on table no $\mathrm{V}$.

\begin{tabular}{|c|c|c|c|c|c|}
\hline \multirow{2}{*}{\multicolumn{2}{|c|}{ Range of motion loss }} & \multicolumn{4}{|c|}{ Supination and pronation } \\
\hline & & $<25 \%$ loss & $<50 \%$ loss & $>50 \%$ loss & Total \\
\hline \multirow{4}{*}{$\begin{array}{l}\text { Flexion / } \\
\text { extension } \\
\text { at elbow }\end{array}$} & $<10^{\circ}$ loss & 25 & 0 & 0 & $\begin{array}{c}25 \\
(71.8 \%)\end{array}$ \\
\hline & $<20^{\circ}$ loss & 2 & 1 & 0 & $\begin{array}{c}3 \\
(9.4 \%)\end{array}$ \\
\hline & $>20^{\circ}$ loss & 1 & 1 & 2 & $\begin{array}{c}4 \\
(12.5 \%)\end{array}$ \\
\hline & Total & 28 & 2 & 2 & $\begin{array}{c}32 \\
(100 \%)\end{array}$ \\
\hline
\end{tabular}

Table V: Range of motion loss at final follow up 


\begin{tabular}{|c|c|c|c|c|c|}
\hline & \multicolumn{5}{|c|}{ Anderson's scoring system } \\
\hline & & Excellent & Good & Optimal & \\
\hline \multirow{3}{*}{$\begin{array}{l}\text { Type of } \\
\text { monteggia } \\
\text { fracture }\end{array}$} & Type I & 23 & 1 & 3 & \multirow{3}{*}{0.00} \\
\hline & Type III & 2 & 0 & 1 & \\
\hline & Type IV & 0 & 2 & 0 & \\
\hline \multirow{2}{*}{$\begin{array}{l}\text { Open and } \\
\text { closed } \\
\text { fracture }\end{array}$} & Open & 0 & 1 & 2 & \multirow{2}{*}{0.002} \\
\hline & Closed & 25 & 2 & 2 & \\
\hline \multirow{2}{*}{$\begin{array}{l}\text { Reduction } \\
\text { method }\end{array}$} & Open & 2 & 1 & 4 & \multirow{2}{*}{0.00} \\
\hline & Closed & 23 & 2 & 0 & \\
\hline \multirow{2}{*}{$\begin{array}{c}\text { Trans } \\
\text { capitellar K- } \\
\text { wire in radius }\end{array}$} & Fixed & 0 & 2 & 3 & \multirow[t]{2}{*}{0.00} \\
\hline & Not fixed & 25 & 1 & 1 & \\
\hline \multirow{3}{*}{ Union time } & $<10$ weeks & 24 & 0 & 1 & \multirow{3}{*}{0.00} \\
\hline & & & & & \\
\hline & $>10$ weeks & 1 & 3 & 3 & \\
\hline
\end{tabular}

Table VI: Anderson's scoring and its comparisons

The functional outcome based on Anderson scoring system it was excellent in $25(78.1 \%)$ cases and three $(9.4 \%)$ cases had good outcome and four (12.5\%) hadoptimal outcome. Three patients developed superficial infection and six patients had bursitis over the site of pin on ulnar aspect which resolved after treatment. Five cases with trans capitellar K-wire had restricted range of motion, on final follow up after treatment.

\section{DISCUSSION}

Monteggia fracture dislocation, though rare fracture dislocation accounting approximately $1 \%$ of all fracture and or dislocation of forearm and radial head dislocation is often missed to diagnose. ${ }^{11,12,15}$ Close reduction and cast immobilization of childhood monteggia fracture dislocation has been a way of treatment but there is high chance of late displacement which requires late operative fixation. ${ }^{16}$ So, primary operative treatment of displaced monteggia fracture dislocation has been a practice..$^{12,16-18}$ In our study there was monteggia fracture dislocation predominately in males 19 (59.37\%), it was comparable with the study of Ring $D$ et $a^{14}$ and Khan SA et al. ${ }^{17}$ Most of the study accounted fall as the common mechanism of injury as Reckling FW et al ${ }^{9}$, Khan et al. ${ }^{14}$ Similar finding was found in our study too with fall contributing to $29(90.63 \%)$ cases. Bruce H.E et $\mathrm{al}^{14}$ showed $79 \%$ type I monteggia fracture dislocation bases on Bado's classification, in our study too type I was the most common type of fracture pattern contributing to $27(84.37 \%)$ followed by type III three (9.4\%) and type IV two (6.3\%).

In our study all cases needed reduction of radial head before the procedure comparable to the study done by Reckling et $\mathrm{al}^{7}$ but none of them needed excision of radial head. Five cases needed supplementation of trans capitellar K-wire fixation into the radius to stabilize it which were removed at three weeks of the procedure among them two were type I, one was type III and two were type IV (6.3\%).

Reckling FW et $\mathrm{al}^{7}$, Ring et $\mathrm{al}^{13}$ Bruce et $\mathrm{al}^{14}$ found proximal radioulnar synostosis in around 6-7\%, nonunion in 2-6\%, delayed union in $4 \%$, superficial infection in $6 \%$, nerve involvement in $17 \%$. In our study $9 \%$ three cases had superficial infection which subsided with treatment. Delayed union in three cases with open fracture. Three patients developed superficial infection and six patients had bursitis over the site of pin on ulnar aspect which resolved after treatment. Five cases with trans capitellar K-wire had restricted range of motion, on final follow up after treatment.

Reckling FW et al , Ring et $\mathrm{al}^{13}$ Bruce et $\mathrm{al}^{14}$ reported excellent results in $37-67 \%$, satisfactory results in $15-30 \%$, unsatisfactory results in 8 to $20 \%$ and failure in 5 to $50 \%$.In our study 25 (78.1\%) cases had excellent outcome and three $(9.4 \%)$ cases had good outcome and four (12.5\%) had optimal outcome. Final outcome is affected by open fractures, trans capitellar $\mathrm{K}$-wire and duration of union as suggested by $\mathrm{p}$-value $<0.05$.

\section{LIMITATIONS}

Small sample size, non-randomized control trails, short duration of follow ups are the limitations

\section{CONCLUSION}

Though monteggia fractures are uncommon fracture dislocation, early diagnosis and early closed reduction of radial head and intramedullary K-wire fixation of ulna is a better option of treatment with average three cortical union in $8.44 \pm 1.94$ weeks. Early mobilization has excellent functional outcome of elbow in children in $25(78.1 \%)$ cases. Pin tract infection, bursitis and restricted range of motion were the complications that encountered during this study.

\section{REFERENCES}

1. GB M. Lussazioni delle ossa delle estremita superiori. In: Monteggia GB., Editor. Instituzioni Chirurgiches. 2nd. Maspero; Milan, Italy. 1814; 5:131- 133. 2. .

2 .J. P. Les fractures du cubitus accompagnees de luxation de l'extremite superieur du radius. These de Paris. G Steinheil P, France, 1909., editor.

3. Bado JL. The Monteggia lesion. Clin Orthop Relat Res. 1967;50:71-86.

4. Rehim SA, Maynard MA, Sebastin SJ, Chung KC. Monteggia fracture dislocations: a historical review. J Hand Surg Am. 2014;39(7):1384-94.

5. Tajima T, Yoshizu T. Treatment of long-standing dislocation of the radial head in neglected Monteggia fractures. J Hand 
Surg Am. 1995;20(3 Pt 2):S91-4.

6. Goyal T, Arora SS, Banerjee S, Kandwal P. Neglected Monteggia fracture dislocations in children: a systematic review. J Pediatr Orthop B. 2015;24(3):191-9.

7. Koslowsky TC, Mader K, Wulke AP, Gausepohl T, Pennig D. Operative treatment of chronic Monteggia lesion in younger children: a report of three cases. J Shoulder Elbow Surg. 2006;15(1):119-21.

8. Bruce HE, Harvey JP, Wilson JC, Jr. Monteggia fractures. J Bone Joint Surg Am. 1974;56(8):1563-76.

9. Reckling FW. Unstable fracture-dislocations of the forearm (Monteggia and Galeazzi lesions). J Bone Joint Surg Am. 1982;64(6):857-63.

10. Delpont M, Louahem D, Cottalorda J. Monteggia injuries. Orthop Traumatol Surg Res. 2018;104(1s):S113-s20.

11. Giustra PE, Killoran PJ, Furman RS, Root JA. The Missed Monteggia Fracture. Radiology. 1974;110(1):45-7.

12. Dormans JP, Rang $M$. The problem of Monteggia fracture-dislocations in children. Orthop Clin North Am. 1990;21(2):251-6.

13. Korani RR. Monteggia fracture dislocation: A study on the functional outcome of surgical treatment in patients attending Osmania General Hospital, Hyderabad, Telangana, India. International Journal of Orthopaedics Sciences 2018;4(1): 05-11

14. Khan SA. Monteggia fracture dislocation in adults: study of functional outcome following surgical treatment in patients attending a tertiary care center in north India. Int J Res Med Sci. 2017;5:2975-81.

15. Fowles JV, Sliman N, Kassab MT. The Monteggia lesion in children. Fracture of the ulna and dislocation of the radial head. J Bone Joint Surg Am. 1983;65(9):1276-82.

16. Letts $M$, Locht $R$, Wiens J. Monteggia fracture-dislocations in children. J Bone Joint Surg Br. 1985;67(5):724-7.

17. Ring $D$, Jupiter JB, Waters PM. Monteggia fractures in children and adults. J Am Acad Orthop Surg. 1998;6(4):215-24.

18. Gryson T, Van Tongel A, Plasschaert F. The management of chronic paediatric Monteggia fracture-dislocation. J Orthop. 2021;24:65-76.

19. Kumar M, Bhatt MF, Gupta S et al. Clinical outcome of acute Monteggia fractures in children after open reduction and internal fixation of ulna. Int J Res Med Sci. 2021 May;9(5). 